\title{
A new approach using coagulation rate constant for evaluation of turbidity removal
}

\author{
Mukheled Al-Sameraiy ${ }^{1}$
}

Received: 12 January 2015 / Accepted: 8 September 2015/Published online: 23 September 2015

(C) The Author(s) 2015. This article is published with open access at Springerlink.com

\begin{abstract}
Coagulation-flocculation-sedimentation processes for treating three levels of bentonite synthetic turbid water using date seeds (DS) and alum (A) coagulants were investigated in the previous research work. In the current research, the same experimental results were used to adopt a new approach on a basis of using coagulation rate constant as an investigating parameter to identify optimum doses of these coagulants. Moreover, the performance of these coagulants to meet (WHO) turbidity standard was assessed by introducing a new evaluating criterion in terms of critical coagulation rate constant $\left(\mathrm{k}_{\mathrm{c}}\right)$. Coagulation rate constants $\left(\mathrm{k}_{2}\right)$ were mathematically calculated in second order form of coagulation process for each coagulant. The maximum $\left(\mathrm{k}_{2}\right)$ values corresponded to doses, which were obviously to be considered as optimum doses. The proposed criterion to assess the performance of coagulation process of these coagulants was based on the mathematical representation of (WHO) turbidity guidelines in second order form of coagulation process stated that $\left(\mathrm{k}_{2}\right)$ for each coagulant should be $\geq\left(k_{c}\right)$ for each level of synthetic turbid water. For all tested turbid water, DS coagulant could not satisfy it. While, A coagulant could satisfy it. The results obtained in the present research are exactly in agreement with the previous published results in terms of finding optimum doses for each coagulant and assessing their performances. On the whole, it is recommended considering coagulation rate constant to be a new approach as an indicator for investigating optimum doses and critical coagulation rate constant to be a new evaluating criterion to assess coagulants' performance.
\end{abstract}

Mukheled Al-Sameraiy

mukheled73@gmail.com; mahas20@bath.ac.uk

1 Environmental Research Center, University of Technology, Baghdad, Iraq
Keywords Coagulation rate constant $\cdot$ Kinetics modeling $\cdot$ Coagulants' performance $\cdot$ Turbidity removal

\section{Introduction}

Coagulation is the process of destabilizing colloids, aggregating them, and binding them together for ease of sedimentation. This is achieved by adding simple salts or by charge neutralization, resulting in a tendency in the aggregates (coagula) to be small and dense. Flocculation is limited to the cases where polymer bridging is the dominant mechanism and aggregates (flocs) tend to be larger and more open in structure. In the area of water and wastewater treatment, coagulation refers to destabilization by the dosing of appropriate additives and flocculation refers to the formation of aggregates usually by some form of fluid motion (Gregory 2006).

The coagulation mechanisms depending on the physical and chemical properties of the solution, pollutant and coagulant include charge neutralization, double layer compression, bridging and sweep (Holt et al. 2002).

Coagulation and flocculation constitute the backbone processes in most water and advanced wastewater treatments plants (Wang et al. 2005) in which they are of great importance in solid-liquid separation practice (Yukselen and Gregory 2004) and widely used to remove turbidity in the form of suspended as well as colloidal materials from synthetic turbid water (Jadhav and Mahajan 2013; Kılıç and Hoşten 2010) and raw surface water (Esther et al. 2013; Zainal-Abideen et al. 2012).

The expression of kinetic was early introduced for the time evolution of particle aggregates on the basis of a mean filed of theory of identical particles in a matrix. The rate of aggregation of particles depends on physical properties of 
the system such as shape and size of particles, composition, interactive forces, frequency of collision and probability of sticking once collision has occurred. These factors can vary based on many conditions such as temperature, solution $\mathrm{pH}$ or other chemical properties that affect particle correlations, and presence of an external field (Smoluchowski 1917).

Modeling is a valuable engineering tool in both design and operation of treatment plants. It also helps to develop a better understanding of the treatment processes and provide a significant potential for solving operational problems as well as reducing operational cost in a specific treatment processes. Coagulation kinetics modeling of water treatment plants can be used for process optimization and testing of control strategies to meet effluent quality requirements at a reasonable cost. The kinetics of coagulation has been investigated for several kinetics functional parameters such as order of coagulation process, coagulation rate constant, coagulation time, coagulation period, collision factor for Brownian transport and collision efficiency. In addition, various forms of the rate law equation have been analytically solved (Okolo et al. 2014; Nnaji et al. 2014; Chukwudi and Onukwuli 2011; Ani et al. 2011)

The objective of the current research was to develop a new approach using coagulation rate constant determined on the basis of experimental results reported by Al-Sameraiy (2012) as an indicator to investigate the optimum doses of date seeds and alum coagulants, and introducing a new evaluating criterion in terms of critical coagulation rate constant to assess the performance of coagulation process of these coagulants in achieving the minimum level of residual turbidity to satisfy WHO turbidity standard guidelines.

\section{Materials and methods}

The three selected levels of bentonite synthetic turbid water namely: low (75 NTU), medium (150 NTU) and high (300 NTU) as well as the doses of natural coagulant (date seeds, DS) and inorganic coagulant (alum, A) in the range $(10-100 \mathrm{mg} / \mathrm{L})$ under various settling times from 30 to 120 min using a standard jar test apparatus to simulate coagulation, flocculation and sedimentation processes were carried out by Al-Sameraiy (2012). In the current research, his experimental data findings were used to investigate coagulation kinetics modeling in terms of second order of coagulation process form for coagulation rate constant and critical coagulation rate constant.

\section{Coagulation kinetics modeling}

It is well known that the fundamentals of the rate of aggregation started from the classic work of Smoluchowski (1917). After a period of the aggregation of particles, size distribution and shape of these particles can be changed basically. To describe the aggregation rate of particles count based on the Brownian controlled and rapid coagulation, the general differential equation can be shown below:

$-\frac{\mathrm{dc}}{\mathrm{d} t}=\mathrm{k}_{\mathrm{c}}{ }^{\alpha}$

where $\alpha$ is the order of coagulation process, $\mathrm{k}$ is the coagulation rate constant in (L/mg.min), $c$ is the total concentration of constituent particles in $(\mathrm{mg} / \mathrm{L})$ at time $t$ (min).

To simplify and solve the Eq. (1), the theoretical values of the order of coagulation process $(\alpha)$ are in the range of $(1 \leq \alpha \leq 2)$ (Chukwudi et al. 2009; WST 2003). Basically, Elimelech et al. (1995) proposed that the aggregation process is predominant in the form of second order by which the collision is proportional to the product of concentrations of two colliding species. Moreover, in real and empirical practice, extensive studies such as (Ani et al. 2012; Ifeanyi et al. 2012; Ugonabo et al. 2013) used $(\alpha=2)$ and found that it was more logical in representing primarily the aggregation rate of particles count on the basis of Brownian controlled and rapid coagulation process. Based on the above aforementioned, substituting $(\alpha=2)$ in the Eq. (1) and integrating it with the following boundary conditions, at initial condition $(t=0$, $\left.c=c_{0}\right)$ and at final condition $(t=t, c=c)$ to obtain Eq. (2):

$\frac{1}{c}=\mathrm{k}_{2} t+\frac{1}{c_{0}}$

Rearranging the Eq. (2) to get Eq. (3), which is used to calculate the values of $\left(\mathrm{k}_{2}\right)$ mathematically in the current research:

$\mathrm{k}_{2}=\frac{1 / c-1 / c_{0}}{t}$

where $\mathrm{k}_{2}$ is the second order coagulation rate constant.

The total concentration of bentonite constituent particles of three levels of synthetic turbid water as blank before treatment $\left(c_{0}\right)$ and after treatment $(c)$ used in Eq. (3) could be expressed in either $(\mathrm{mg} / \mathrm{L})$ and the unit of $\left(\mathrm{k}_{2}\right)$ would be (L/mg.min) or (NTU) as turbidity reading (WST 2003; $\mathrm{Ni}$ 'am et al. 2007) and the unit of $\left(\mathrm{k}_{2}\right)$ would be $\left(\mathrm{NTU}^{-1} \cdot \mathrm{min}^{-1}\right)$. 


\section{Results and discussion}

\section{Coagulation rate constant as an investigating parameter for optimum coagulant dose}

Dosage is one of the most important parameters, which has been considered to determine the optimum conditions for the coagulation and flocculation. Basically, insufficient dosage or overloading would result in the poor performance in flocculation. Therefore, it was crucial to determine the optimum dosage in order to minimize the dosing cost and obtain the optimum performance in treatment (American Water Works Association (AWWA) 2000). In conventional water treatment practice, finding the optimum dose for each coagulant is a problem that must be solved and determined by empirical experiments. The experimental results obtained and reported by Al-Sameraiy (2012) are briefly summarized in Tables 1, 2, 3 based on the best settling time of (120 min). It is clear to see from these tables that the values of residual turbidity of DS coagulant are higher than that of A coagulant at all the investigated doses from 10 to $100 \mathrm{mg} / \mathrm{L}$ for three tested levels of low, medium and high synthetic turbid water. This variation in performance of these coagulants is expected due to every coagulant has ability in terms of coagulation activity for turbidity removal. In consequence, this ability plays a vitally important role in investigating the optimum dose for coagulation-flocculation process (Al-Sameraiy 2012). The objective of this section is only to use coagulation rate constant $\left(\mathrm{k}_{2}\right)$ as an investigating parameter to identify optimum doses of (DS and A) coagulants in spite of their performances in terms of satisfying the (WHO) turbidity standard of drinking water.

In the current research, the experimental results recorded in Tables 1, 2, 3 were used to find the values of second order coagulation rate constant $\left(\mathrm{k}_{2}\right)$ in which these values

Table 1 Investigated optimum dose for (DS and A) coagulants as a function of residual turbidity according to WHO turbidity standard at low synthetic turbid water (Al-Sameraiy 2012)

\begin{tabular}{|c|c|c|c|c|c|c|}
\hline $\begin{array}{l}\text { Investigated } \\
\text { doses }(\mathrm{mg} / \mathrm{L})\end{array}$ & DS coagulant & $\begin{array}{l}\text { Optimum } \\
\text { dose }(\mathrm{mg} / \mathrm{L})\end{array}$ & $\begin{array}{l}\text { WHO turbidity } \\
\text { standard } \leq 5 \text { NTU }\end{array}$ & A coagulant & $\begin{array}{l}\text { Optimum } \\
\text { dose }(\mathrm{mg} / \mathrm{L})\end{array}$ & $\begin{array}{l}\text { WHO turbidity } \\
\text { standard } \leq 5 \mathrm{NTU}\end{array}$ \\
\hline & \multicolumn{6}{|c|}{ Residual turbidity $(c)$ in (NTU) after settling time (120 min) } \\
\hline 10 & 11.40 & 30 & Not satisfied & 2.10 & 10 & Satisfied \\
\hline 20 & 7.90 & & & 5.87 & & \\
\hline 30 & 5.20 & & & 8.13 & & \\
\hline 40 & 7.40 & & & 7.76 & & \\
\hline 50 & 6.45 & & & 8.68 & & \\
\hline 60 & 8.20 & & & 7.23 & & \\
\hline 70 & 8.98 & & & 9.36 & & \\
\hline 80 & 9.70 & & & 7.56 & & \\
\hline 90 & 9.16 & & & 9.81 & & \\
\hline 100 & 10.30 & & & 9.41 & & \\
\hline
\end{tabular}

Table 2 Investigated optimum dose for (DS and A) coagulants as a function of residual turbidity according to WHO turbidity standard at medium synthetic turbid water (Al-Sameraiy 2012)

\begin{tabular}{|c|c|c|c|c|c|c|}
\hline $\begin{array}{l}\text { Investigated } \\
\text { doses }(\mathrm{mg} / \mathrm{L})\end{array}$ & DS coagulant & $\begin{array}{l}\text { Optimum } \\
\text { dose }(\mathrm{mg} / \mathrm{L})\end{array}$ & $\begin{array}{l}\text { WHO turbidity } \\
\text { standard } \leq 5 \mathrm{NTU}\end{array}$ & A coagulant & $\begin{array}{l}\text { Optimum } \\
\text { dose }(\mathrm{mg} / \mathrm{L})\end{array}$ & $\begin{array}{l}\text { WHO turbidity } \\
\text { standard } \leq 5 \mathrm{NTU}\end{array}$ \\
\hline & \multicolumn{6}{|c|}{ Residual turbidity $(c)$ in (NTU) after settling time (120 min) } \\
\hline 10 & 25.90 & 60 & Not satisfied & 6.00 & 20 & Satisfied \\
\hline 20 & 23.50 & & & 4.18 & & \\
\hline 30 & 21.80 & & & 5.80 & & \\
\hline 40 & 20.60 & & & 8.59 & & \\
\hline 50 & 20.80 & & & 11.58 & & \\
\hline 60 & 14.90 & & & 11.00 & & \\
\hline 70 & 17.00 & & & 11.38 & & \\
\hline 80 & 17.60 & & & 10.90 & & \\
\hline 90 & 26.40 & & & 10.40 & & \\
\hline 100 & 27.00 & & & 10.61 & & \\
\hline
\end{tabular}


Table 3 Investigated optimum dose for (DS and A) coagulants as a function of residual turbidity according to WHO turbidity standard at high synthetic turbid water (Al-Sameraiy 2012)

\begin{tabular}{|c|c|c|c|c|c|c|}
\hline $\begin{array}{l}\text { Investigated } \\
\text { doses (mg/L) }\end{array}$ & DS coagulant & $\begin{array}{l}\text { Optimum } \\
\text { dose (mg/L) }\end{array}$ & $\begin{array}{l}\text { WHO turbidity } \\
\text { standard } \leq 5 \text { NTU }\end{array}$ & A coagulant & $\begin{array}{l}\text { Optimum } \\
\text { dose (mg/L) }\end{array}$ & $\begin{array}{l}\text { WHO turbidity } \\
\text { standard } \leq 5 \text { NTU }\end{array}$ \\
\hline & \multicolumn{6}{|c|}{ Residual turbidity (c) in (NTU) after settling time (120 min) } \\
\hline 10 & 72.70 & 80 & Not satisfied & 7.70 & 60 & Satisfied \\
\hline 20 & 70.70 & & & 7.00 & & \\
\hline 30 & 65.60 & & & 6.50 & & \\
\hline 40 & 60.50 & & & 6.00 & & \\
\hline 50 & 63.00 & & & 5.50 & & \\
\hline 60 & 57.20 & & & 4.41 & & \\
\hline 70 & 52.70 & & & 5.10 & & \\
\hline 80 & 50.20 & & & 7.10 & & \\
\hline 90 & 57.20 & & & 7.20 & & \\
\hline 100 & 60.50 & & & 7.70 & & \\
\hline
\end{tabular}

Fig. 1 The relationship between $\left(\mathrm{k}_{2}\right)$ and DS coagulant doses at low synthetic turbid water

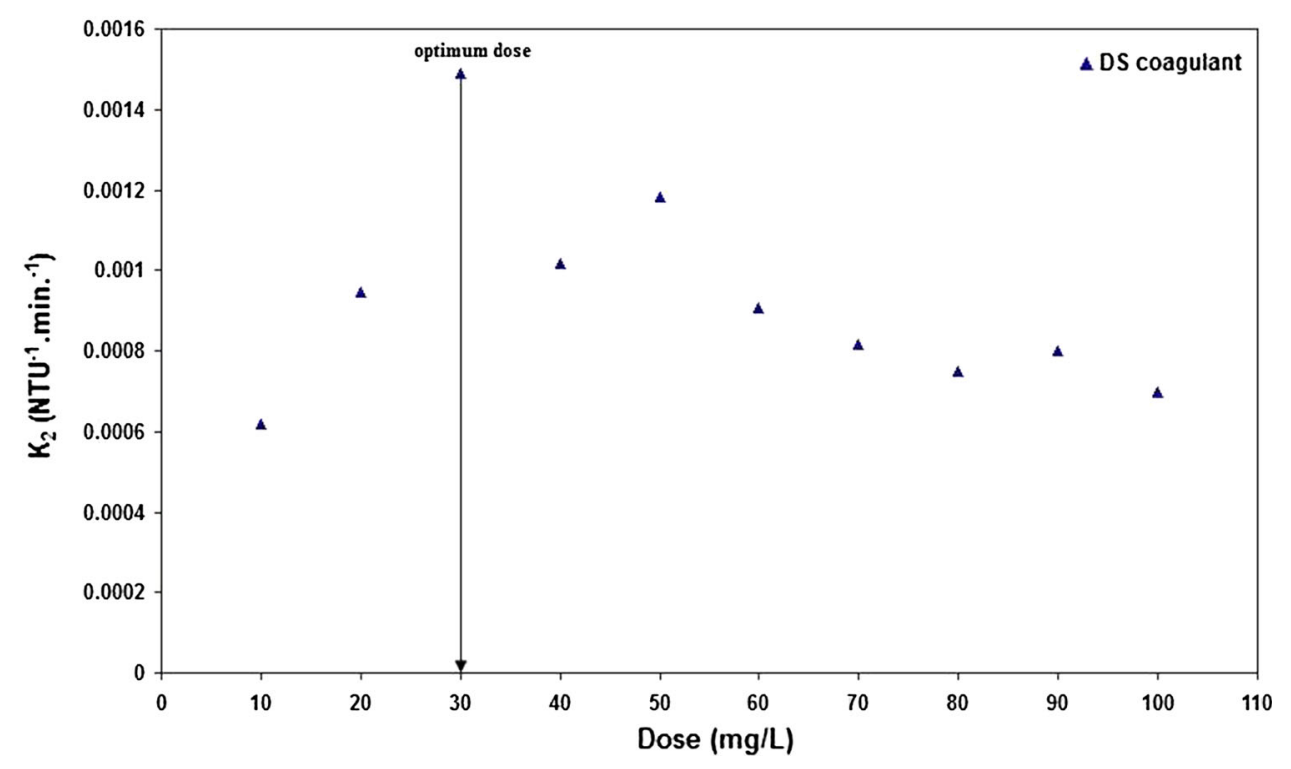

of $\left(k_{2}\right)$ for DS and A coagulants were mathematically determined by substituting the residual turbidities of these coagulants for every level of low, medium and high synthetic turbid water at the end of settling time (120 min) directly in Eq. (3). The relationship between calculated $\left(\mathrm{k}_{2}\right)$ versus the doses of DS and A coagulants were shown in Figs. 1, 2, 3, 4, 5, 6.

In low synthetic turbid water, Fig. 1 shows that the maximum value of $\left(\mathrm{k}_{2}\right)$ for DS coagulant was 0.00149 $\left(\mathrm{NTU}^{-1} \cdot \mathrm{min}^{-1}\right)$ corresponded to the dose of $30 \mathrm{mg} / \mathrm{L}$. This dose is to be considered an optimum dose compared with other doses. Figure 2 indicates that the maximum value of $\left(\mathrm{k}_{2}\right)$ for A coagulant was reported as $0.00386\left(\mathrm{NTU}^{-1}\right.$. $\min ^{-1}$ ) occurred at the dose of $10 \mathrm{mg} / \mathrm{L}$, which is an optimum dose for alum coagulation process.
In medium synthetic turbid water, Figs. 3, 4 demonstrate that the highest values of $\left(\mathrm{k}_{2}\right)$ for $\mathrm{DS}$ and A coagulants were found to be 0.00050 and $0.00194\left(\mathrm{NTU}^{-1} \cdot \mathrm{min}^{-1}\right)$ that corresponded to the doses of 60 and $20 \mathrm{mg} / \mathrm{L}$ respectively. These doses are the optimum doses for DS $(60 \mathrm{mg} / \mathrm{L})$ and A $(20 \mathrm{mg} / \mathrm{L})$ coagulation process.

Similar results were obtained with high synthetic turbid water as shown in Figs. 5, 6. The maximum value of $\left(\mathrm{k}_{2}\right)$ for DS coagulant was $0.00014\left(\mathrm{NTU}^{-1} \cdot \mathrm{min}^{-1}\right)$ in which it occurred at dose of $80 \mathrm{mg} / \mathrm{L}$, which represents an optimum dose. Whilst Fig. 6 states that the highest value of $\left(k_{2}\right)$ for A coagulant was recorded as $0.00186\left(\mathrm{NTU}^{-1} \cdot \mathrm{min}^{-1}\right)$ and corresponded to the optimum dose of $60 \mathrm{mg} / \mathrm{L}$.

In general, it can be seen from the results reported in Figs. 1, 2, 3, 4, 5, 6 that the values of $\left(k_{2}\right)$ for each of DS 
Fig. 2 The relationship between $\left(\mathrm{k}_{2}\right)$ and A coagulant doses at low synthetic turbid water

Fig. 3 The relationship between $\left(\mathrm{k}_{2}\right)$ and DS coagulant doses at medium synthetic turbid water

Fig. 4 The relationship between $\left(\mathrm{k}_{2}\right)$ and A coagulant doses at medium synthetic turbid water
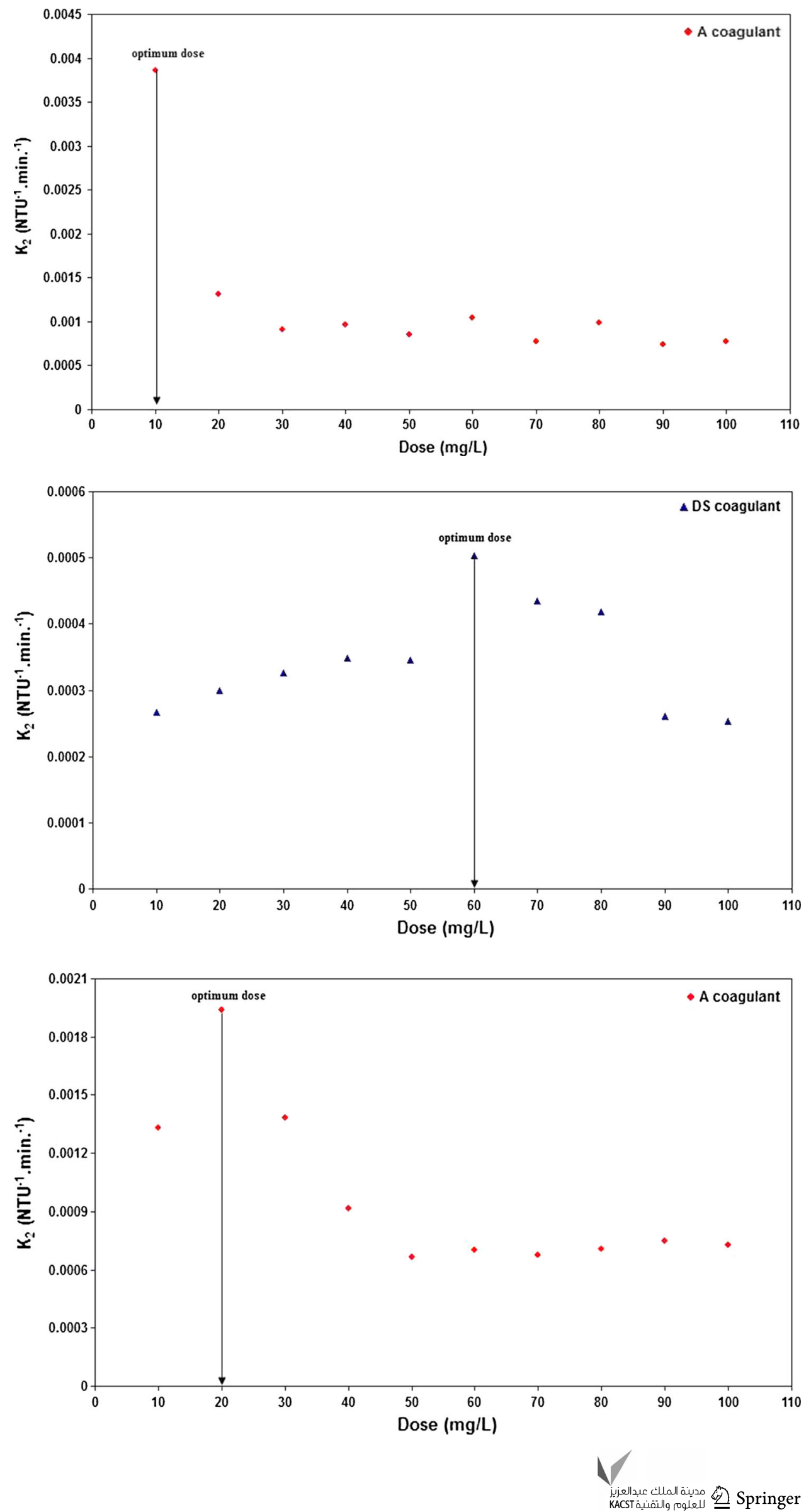
Fig. 5 The relationship between $\left(\mathrm{k}_{2}\right)$ and DS coagulant doses at high synthetic turbid water

Fig. 6 The relationship between $\left(\mathrm{k}_{2}\right)$ and A coagulant doses at high synthetic turbid water
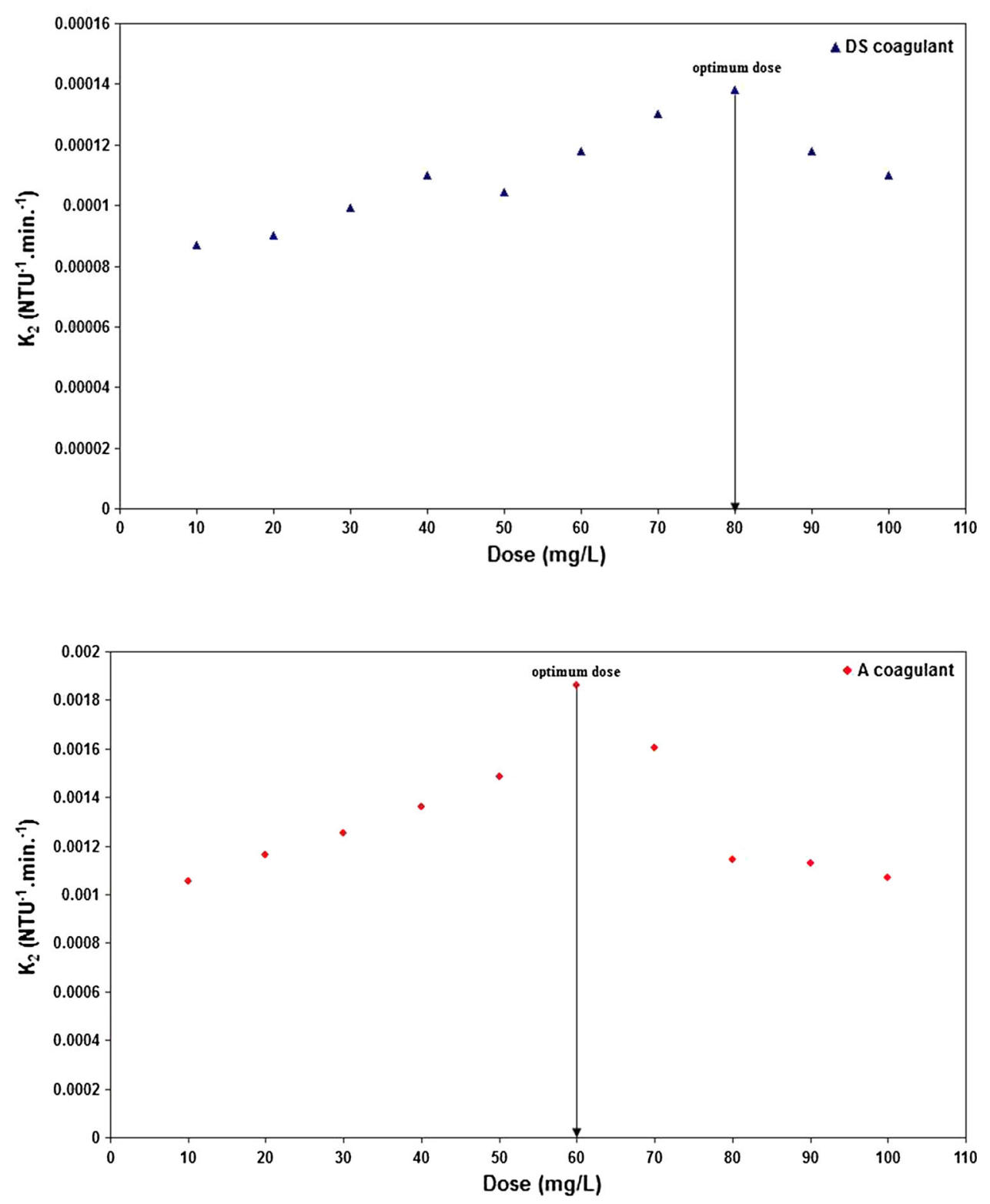

and A coagulants increased gradually with an increase in the initial coagulant doses to reach a maximum value at a certain dose, which represents an optimum dose and then decreased steadily to reach a minimum values. This behavior is expected in which it could be explained by the fact that the optimal dose of coagulant in suspension causes larger amount of solid to aggregate and settle. However an overoptimal amount coagulant would cause the aggregated particles to re-disperse in the suspension and would also disturb particle settling (Al-Sameraiy 2012; Chaudhuri and Khairuldin 2009; Divakaran and Pillai 2002). On the other hand, in terms of residual turbidity, it decreases with increasing the coagulant doses, but after a certain dose, the suspension showed a tendency to restabilize and further increase in coagulant doses adversely affected turbidity removal as residual turbidity (Al-Sameraiy 2012; Diaz et al. 1999). The optimum doses of each coagulant in these figures were selected on a basis of the maximum values of $\left(\mathrm{k}_{2}\right)$, which corresponded to these doses.

It is obvious from the results reported that the numeric values of coagulation rate constant $\left(\mathrm{k}_{2}\right)$ depends basically on the several affecting parameters including: the initial turbidity level of synthetic turbid water, type of coagulant and coagulant doses. This is expected mathematically to get different values of $\left(\mathrm{k}_{2}\right)$ when used Eq. (3) on the basis of second order form of coagulation process. Consequently, the values of $\left(\mathrm{k}_{2}\right)$ would vary with the type of coagulant used, initial turbidity level of synthetic turbid water and coagulant dose. Table 4 shows the relationship between the second order coagulation rate constant and the affecting parameters. 
Table 4 Second order coagulation rate constant $\left(\mathrm{k}_{2}\right)$ as a function of several affecting parameters

\begin{tabular}{lll}
\hline Synthetic turbid water (NTU) & $\mathrm{k}_{2}\left(\mathrm{NTU}^{-1} \cdot \mathrm{min}^{-1}\right)$ \\
\cline { 2 - 3 } & DS coagulant & A coagulant \\
\hline Low (75) & 0.00149 & 0.00386 \\
Medium (150) & 0.00050 & 0.00194 \\
High (300) & 0.00014 & 0.00186 \\
\hline
\end{tabular}

In terms of real applications and process scale-up, it is of importance to mention that the values of $\left(\mathrm{k}_{2}\right)$ for each coagulant in the current research should be specifically selected based on the initial turbidity level of synthetic water involving low (75 NTU), medium (150 NTU) and high (300 NTU). Accordingly, it is not required to modify or correct the order of coagulation process.

The results obtained in Figs. 1, 2, 3, 4, 5, 6 are exactly in accordance with the experimental data reported in Tables 1, 2, 3 relating to find the optimum doses for each coagulant by which the using of both coagulation rate constant $\left(\mathrm{k}_{2}\right)$ in the current research and residual turbidity obtained by Al-Sameraiy (2012) leading to identify the optimum doses for each coagulant accordingly. These findings using the highest numeric values of coagulation rate constant $\left(\mathrm{k}_{2}\right)$ gave a successful indicator to investigate the optimum doses for each coagulant of coagulation process. The order of coagulation process, $\alpha=2$ showed that an excellent representation in terms of satisfaction of the experimental results in the current research.

\section{Critical coagulation rate constant as an evaluating criterion for coagulants' performance}

World Health Organization (WHO) guidelines recommend the upper limit of turbidity for finished water is $5 \mathrm{NTU}$ (WHO 1996, 2006, 2008). In terms of mathematical representation of this recommendation, critical coagulation rate constant $\left(\mathrm{k}_{\mathrm{c}}\right)$ could be introduced according to the following assumption:

$c$ : is equal to (5 NTU) referring to the upper limit of (WHO) water turbidity (WHO 1996, 2006, 2008).

$c_{0}$ : is the concentration of synthetic turbid water levels including: low (75 NTU), medium (150 NTU) and high (300 NTU) (Al-Sameraiy 2012).

$t$ : is the end of predetermined settling time and equal to (120 min) (Al-Sameraiy 2012).

Substituting the values of $\left(c, c_{0}, t\right)$ in Eq. (3) to obtain the values of $\left(\mathrm{k}_{\mathrm{c}}\right)$ as shown in Table 5:

To assess the performance of coagulation process for each coagulant of date seeds and alum at their optimum doses in terms of satisfying (WHO) turbidity drinking
Table 5 Critical coagulation rate constant $\left(\mathrm{k}_{\mathrm{c}}\right)$ as a function of synthetic turbid water levels

\begin{tabular}{lcl}
\hline Synthetic turbid water & $c_{0}(\mathrm{NTU})$ & $\mathrm{k}_{\mathrm{c}}\left(\mathrm{NTU}^{-1} \cdot \mathrm{min}^{-1}\right)$ \\
\hline Low & 75 & 0.00156 \\
Medium & 150 & 0.00161 \\
High & 300 & 0.00164 \\
\hline
\end{tabular}

water guidelines (WHO 1996, 2006, 2008), the following criterion was proposed:

$\left(k_{2}\right)$ for each coagulant $\geq\left(k_{c}\right)$

for each level of synthetic turbid water

The validity of the proposed criterion was tested with the results obtained by Al-Sameraiy (2012) in terms of residual turbidity of coagulation process as shown in Tables 1, 2, 3 in order to meet (WHO) turbidity standard $(\leq 5 \mathrm{NTU})$ of drinking water.

Based on the results shown in Figs. 1, 2, 3, 4, 5, 6, it can be clearly observed that the maximum values of $\left(\mathrm{k}_{2}\right)$ corresponded to the optimum doses for each coagulant. These values of $\left(\mathrm{k}_{2}\right)$ at their predetermined optimum doses are assessed according to the proposed criterion (Eq. 4) in Figs. 7, 8, 9 .

In low synthetic turbid water, Fig. 7 shows the value of $\left(\mathrm{k}_{2}\right)$ for DS coagulant at the optimum dose $(30 \mathrm{mg} / \mathrm{L})$ is $0.00149\left(\mathrm{NTU}^{-1} \cdot \mathrm{min}^{-1}\right)$ lower than $\left(\mathrm{k}_{\mathrm{c}}\right)$ value of 0.00156 $\left(\mathrm{NTU}^{-1} \cdot \mathrm{min}^{-1}\right)$ as shown in Table 5 and thus it could not satisfy the proposed criterion (Eq. 4). This means that its performance could not meet (WHO) turbidity standard. Similarly, according to Table 1, it produced residual turbidity of 5.2 NTU higher than 5 NTU as (WHO) turbidity standard. While for alum coagulant, the value of $\left(\mathrm{k}_{2}\right)$ at the optimum dose $(10 \mathrm{mg} / \mathrm{L})$ is $0.00386\left(\mathrm{NTU}^{-1} \cdot \mathrm{min}^{-1}\right)$ higher than $\left(\mathrm{k}_{\mathrm{c}}\right)$ value of $0.00156\left(\mathrm{NTU}^{-1} \cdot \mathrm{min}^{-1}\right)$ and it could successfully satisfy the proposed criterion. As a result, the performance of A coagulant could meet (WHO) turbidity standard. Also, as shown in Table 1, it produced residual turbidity of 2.1 NTU and satisfied (WHO) turbidity standard accordingly.

In medium synthetic turbid water, Fig. 8 states that the $\left(\mathrm{k}_{2}\right)$ values for DS and A coagulants at their optimum doses of 60 and $20 \mathrm{mg} / \mathrm{L}$ are 0.00050 and 0.00194 $\left(\mathrm{NTU}^{-1} \cdot \mathrm{min}^{-1}\right)$ lower and higher than $\left(\mathrm{k}_{\mathrm{c}}\right)$ value of $0.00161\left(\mathrm{NTU}^{-1} \cdot \mathrm{min}^{-1}\right)$ as shown in Table 5 respectively. DS coagulant could not satisfy the proposed criterion. Likewise, according to Table 2, it produced residual turbidity of 14.9 NTU higher than the upper limit of (WHO) turbidity standard. On the other hand, alum coagulant could effectively satisfy the proposed criterion. In the same way as shown in Table 2, it satisfied (WHO) turbidity standard by producing residual turbidity of 4.18 NTU. 
Fig. $7\left(\mathrm{k}_{\mathrm{c}}\right)$ as an evaluating parameter compared with $\left(\mathrm{k}_{2}\right)$ for DS and A coagulants at predetermined optimum doses and low synthetic turbid water

Fig. $8\left(k_{c}\right)$ as an evaluating parameter compared with $\left(\mathrm{k}_{2}\right)$ for DS and A coagulants at predetermined optimum doses and medium synthetic turbid water
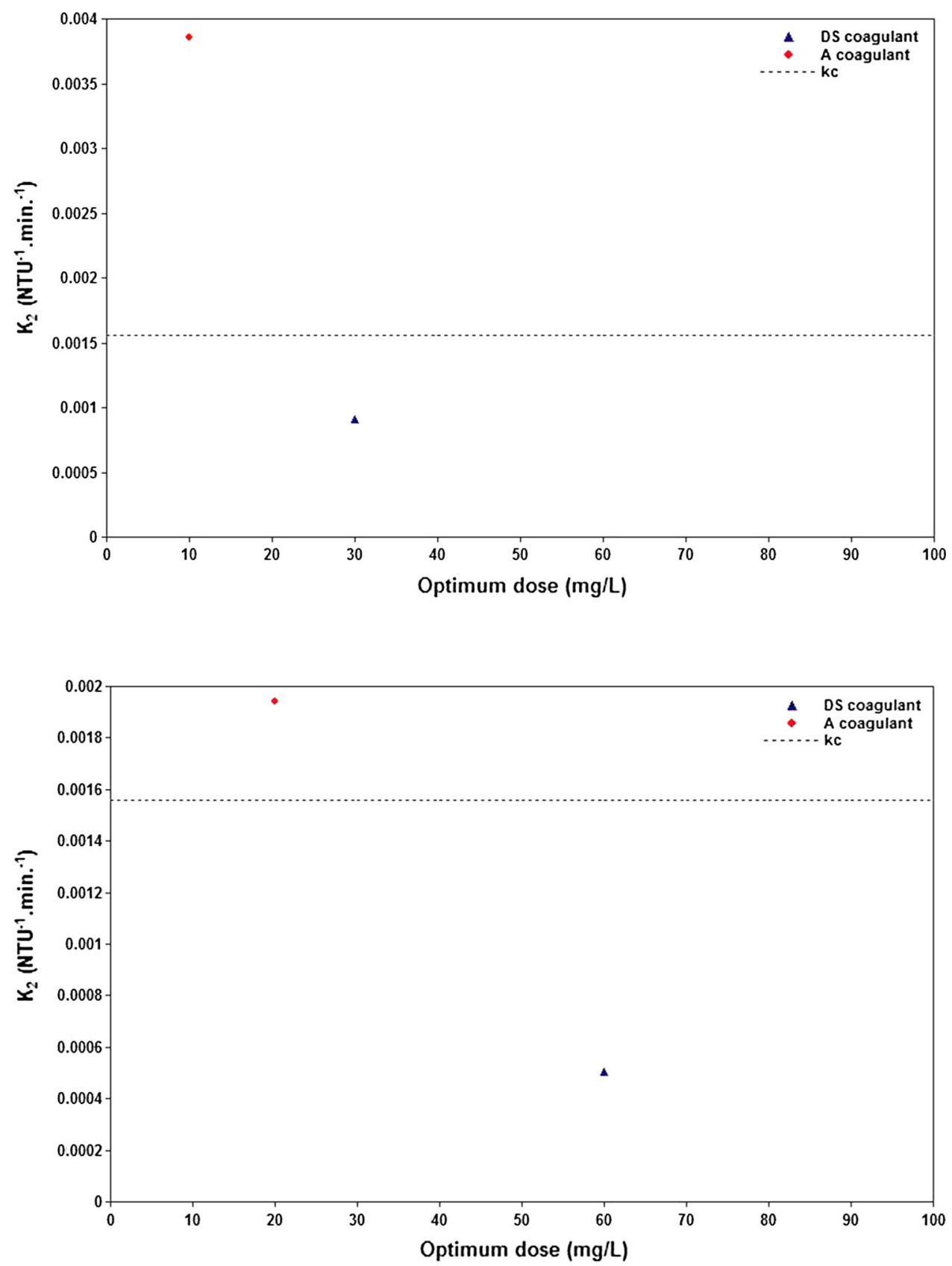

Similar observations were reported with high synthetic water as shown in Fig. 9. At the optimum dose $(80 \mathrm{mg} / \mathrm{L})$ of DS coagulant, the value of $\left(\mathrm{k}_{2}\right)$ is 0.00014 $\left(\mathrm{NTU}^{-1} \cdot \mathrm{min}^{-1}\right)$ smaller than $\left(\mathrm{k}_{\mathrm{c}}\right)$ value of 0.00164 $\left(\mathrm{NTU}^{-1} \cdot \mathrm{min}^{-1}\right)$ as shown in Table 5 . Consequently, its performance could not meet (WHO) turbidity standard since it could not satisfy the proposed criterion. Also, according to Table 3 , it produced residual turbidity of 50.2 NTU higher than the standard value of turbidity according to (WHO) guidelines. Whilst at the optimum dose $(60 \mathrm{mg} / \mathrm{L})$ of A coagulant, the value of $\left(\mathrm{k}_{2}\right)$ is 0.00186
$\left(\mathrm{NTU}^{-1} \cdot \mathrm{min}^{-1}\right)$ greater than $\left(\mathrm{k}_{\mathrm{c}}\right)$. Hence, it could efficiently satisfy the proposed criterion. In the same way as shown in Table 3, it produced residual turbidity of 4.41 NTU and satisfied (WHO) turbidity standard accordingly.

\section{Conclusion}

The results obtained in the current research in terms of the second order coagulation rate constant as an investigating parameter to find the optimum doses of coagulation process 
Fig. $9\left(\mathrm{k}_{\mathrm{c}}\right)$ as an evaluating parameter compared with $\left(\mathrm{k}_{2}\right)$ for DS and A coagulants at predetermined optimum doses and high synthetic turbid water

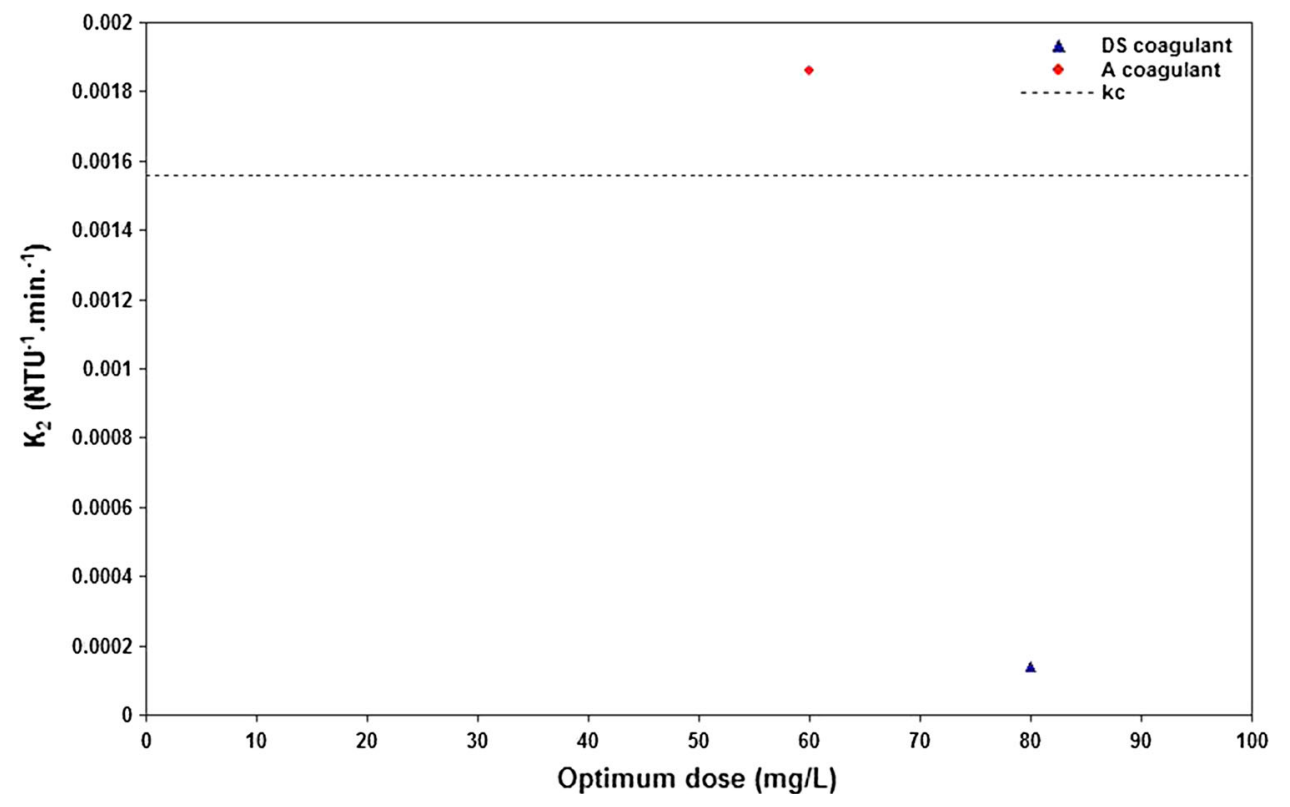

for date seeds and alum coagulants as well as the critical coagulation rate constant as an evaluating criterion to assess the performance these coagulants were tested and validated with the published results by Al-Sameraiy (AlSameraiy 2012). They are exactly in accordance with his findings. Therefore, it is reasonable to consider this approach in the current search to be a new approach in coagulation kinetics modeling for monitoring the performance of water treatment plants to meet effluent quality requirements.

Open Access This article is distributed under the terms of the Creative Commons Attribution 4.0 International License (http:// creativecommons.org/licenses/by/4.0/), which permits unrestricted use, distribution, and reproduction in any medium, provided you give appropriate credit to the original author(s) and the source, provide a link to the Creative Commons license, and indicate if changes were made.

\section{References}

Al-Sameraiy M (2012) A novel water pretreatment approach for turbidity removal using date seeds and pollen sheath. J Water Resour Prot 4:79-92

American Water Works Association (AWWA) (2000) Operational control of coagulation and filtration processes. Manual M37, 2nd edn. Denver

Ani JU, Chukwudi MM, Onukwuli OD (2011) Coagulation-flocculation performance of snail shell biomass for waste water purification. N Y Sci J 4(2):81-90

Ani JU, Nnaji NJ, Okoye COB, Onukwuli OD (2012) The coagulation performance of Okra Mucilage in an industrial effluent by Turbidimetry. Int J Chem Sci 10(3):1293-1308

Chaudhuri M, Khairuldin PSAB (2009) Coagulation-clarification of coloured water by natural coagulant (Moringa oleifera) seed extract. Nat Environ Pollut Technol 8(1):137-139
Chukwudi MM, Onukwuli OD (2011) Coag-flocculation studies of Afzelia Bella Coagulant (ABC) in Coal Effluent using single and simulated multi angle nephelometry. J Miner Mater Character Eng 10(3):279-298

Chukwudi MM, Nnaji PC, Onukwuli OD (2009) Coag-flocculation kinetics and functional parameters response of Periwinkle shell coagulant (PSC) to $\mathrm{pH}$ variation in organic rich coal effluent medium. Nat Sci 7(6):1-18

Diaz A, Rincon N, Escorihuela A, Fernandez N, Forster CF (1999) A preliminary evaluation of turbidity removal by natural coagulants indigenous to Venezuela. Process Biochem 35(3):391-395

Divakaran R, Pillai SVN (2002) Flocculation of river silt using chitosan. Water Res 36(9):2414-2418

Elimelech MJ, Gregory J, Jia X, Williams RA (1995) Particle deposition and aggregation: measurement, modeling, and simulation. Butterworth-Heinemann Ltd, Oxford

Esther YA, Cokou IN, Agbangnan P, Koudoro AY, Dèdjiho CA, Aïna MP, Mama D, Sohounhloué DC-K (2013) Evaluation of the Opuntia dillenii as natural coagulant in water clarification: case of treatment of highly turbid surface water. J Water Resour Protect 5:1242-1246

Gregory J (2006) Particles in water: properties and processes. IWA Pub., CRC Press Taylor \& Francis, Boca Raton, London

Holt PK, Barton GW, Wark M, Mitchell CA (2002) a quantitative comparison between chemical dosing and electrocoagulation. Colloids Surf A: Physicochem Eng Aspect 211:233-248

Ifeanyi UV, Chukwudi MM, Okechukwu OD (2012) Effect of CoagFlocculation kinetics on telfairia occidentalis seed coagulant (TOC) in Pharmaceutical Wastewater. Int J Multidisciplin Sci Eng 3(9):22-33

Jadhav MV, Mahajan YS (2013) Investigation of the performance of chitosan as a coagulant for flocculation of local clay suspensions of different turbidities. KSCE J Civil Eng 17(2):328-334

Kılıç MG, Hoşten C (2010) A comparative study of electrocoagulation and coagulation of aqueous suspensions of kaolinite powders. J Hazard Mater 176:735-740

Ni' am MF, Othman F, Sohaili J, Fauzia Z (2007) Removal of Cod and turbidity to improve wastewater quality using electrocoagulation technique. Malays J Anal Sci 11(1):198-205

Nnaji PC, Okolo BI, Chukwudi MM (2014) Nephelometric performance evaluation of oxidized starch in the treatment of coal Washery Effluent. Nat Resour 5:79-89 
Okolo BI, Nnaji PC, Menkiti MC, Ugonabo VI, Onukwuli OD (2014) Parametric response evaluation for Xanthosoma spp. Induced Coag-Flocculation of Brewery Effluent. Green Sustain Chem $4: 7-14$

Smoluchowski MV (1917) Verucheiner Mathemtischen Theorie der Koagulations KineticKolloider Lousungen. Int J Res Phys Chem Chem Phys 92:29-168

Ugonabo VI, Chukwudi MM, Atuanya CU, Onukwuli DO (2013) Comparative studies on Coag-flocculation Kinetics of pharmaceutical industry effluent by Achatina maginata shell biomass and aluminum sulphate. Int J Eng Technol 13(2):134-147

Wang LK, Hung Y-T, Shammas NK (2005) Physicochemical treatment processes. Handbook of environ mental engineering, 3rd edn. The Humana Press Inc., Totowa

Water Specialist Technology (WST) (2003) About coagulation and flocculation. Information Bulletins, Sanford, pp 1-10

World Health Organization (WHO) (1996) Water quality monitoring - a practical guide to the design and implementation of freshwater quality studies and monitoring programs. In: Bartram J, Balance R (eds). Published on behalf of United Nations
Environment Programme and the World Health Organization ${ }^{\odot}$ UNEP/WHO. ISBN 41922320

World Health Organization (WHO) (2006) Guidelines for drinking water quality, vol 1, 1-3rd edn. Recommendations, WHO Library Cataloguing-in-Publication Data, Electronic version for the Web. ISBN 9241546964 (NLM classification: WA 675)

World Health Organization (WHO) (2008) Guidelines for drinking water quality, vol 1, 3rd edn. Recommendations, WHO Library Cataloguing-in-Publication Data [electronic resource]. ISBN 9789241547611 (WEB version) (NLM classification: WA 675)

Yukselen MA, Gregory J (2004) The effect of rapid mixing on the break-up and re-formation of flocs. J Chem Technol Biol 79:782-788

Zainal-Abideen M, Aris A, Yusof F, Abdul-Majid Z, Selamat A, Omar SI (2012) Optimizing the coagulation process in a drinking water treatment plant-comparison between traditional and statistical experimental design jar tests. Water Sci Technol 65(3):496-503 